\title{
The academic precariat post-COVID-19
}

\author{
Aidan Cornelius-Bell and Piper A Bell
}

\section{Introduction}

The nature of academic work has again shifted, this time as a result of the COVID-19 global health crisis disproportionately affecting the academic precariat. The continually accelerating conditions of global capitalism have created increasing precariatization in academic workers of the knowledge economy. Alongside issues of mental health, instability, and a denial of the possibility of a stable future, the precariat are also those who are "expected to have a level of education that is greater than the labour they are expected to perform or expect to obtain" (Standing 2014:10). The conditions for work have changed dramatically as a result of the pandemic with wide-ranging social and economic impacts. Global capitalism continues its destructive appetite for adaptation and subsumption of human energy and labor, pausing only briefly for localized lockdowns which, we argue, has created increasingly dangerous and tenuous working conditions for the academic precariat. From an initial lack of support for the precarious workforce to work from home through to a current emphasizing of "if you won't do it, we will find someone who will", the precarious worker in academia is under greater pressure than ever before1. The continued neoliberalising of and capitalist creep into global higher education has created conditions of extreme surplus labor; labor which is highly educated, capable, and anxious to work (Standing 2014). Alongside this slide into almost pre-Fordist employment (Betti 2016) conditions comes a polarization towards ideological extremism, a twisted commitment to managerialism, and a hyper-focus on "job ready graduates" has crept into the structures and core nature of higher education (Brett 2021; Giroux 2014; Norton 2020). An obsession of politicians-come-Vice Chancellors through the entire senior leadership of universities in a vain march towards "profit" through the production of flash buildings and fast-paced organizational change into a zombification of higher education. Amongst this corporate-political class, as Brabazon (2020:131) has characterized, "There is always another Key Performance Indicator, change management initiative, and restructure", a moving feast for academics, professionals, and students who work in the higher education sector, and a constant re-evaluation of conditions for employment. Gone is the period of academia as a secure source of employment, at least for wealthy white men, with its tenured positions to public appearance offering a cushy and relaxed life lent over a book or occasionally leading discussions with small groups of students. It is replaced now by "dualization" of academic work where "insiders [are] in secure, stable employment and outsiders [are] in fixed-term, precarious employment" (Afonso 2013). The promise of a rapid increase in doctoral "students" for an educated populous, strong democracy and knowledgeable pool for potential academic employment has instead resulted in a collapse of academic work into a cat fight for the highest outputs, contributions to journals and books, teaching evaluation results, and a continuous competition for more work (Rao, Hosein, and Raaper 2021).

COVID-19 added yet more vectors of insecurity, angst, and anger for the already precarious academics of the twenty-first-century university. In addition to changing working conditions, it highlighted the tragic fact that it is not just "management" academics who leverage the precariat, rather the entirety of academia, including beloved academic mentors who face increasing incentives to abuse their stable power. Rather than fight back, the secure working bloc turns on the precariat, not just out of fear for themselves, but because they have accepted new capitalist terms and are increasingly succumbing to university management hegemony (here taken in terms of Gramsci 1996). Below, we briefly explore the changes to the university system during the pandemic, explore our experiences of moving online and the changing pressures of working from home in insecure work, evaluate the disproportionate impact of insecure 
pandemic affected work on academic women, and propose a re-centering of doctoral education and traineeship as a productive road to intervene in the desperate future of academia.

\section{The global economy, a pandemic, and technological changes to academic work}

During the COVID-19 global health crisis, the fundamental nature of work changed as countries around the world entered lockdown. These changes were disproportionate for the service industry, front line, and scientific workers whose work, in general terms, continued to operate in a pre-pandemic mode (Myers et al. 2020). Another subset of people lost their means of employment altogether, and already vulnerable people were at a particular disadvantage, including the working class and those in insecure work, as disproportionately affected (Williams 2020). Indeed, the effects of epidemics and pandemics on work has had a notable impact over time which, according to economists, cannot be fully measured (Keogh-Brown et al. 2010). With the recent pandemic, a rapid decentralization of knowledge work occurred, and in countries where the effects of COVID-19 lockdowns and behavioral modifications have continued, there has been a sustained exit of knowledge workers from cities and urban centers involving, in particular, the wealthy middle class. Notably, epidemiologists have highlighted the role of cities in the spread and sustain of COVID-19, in particular in the networked ways in which larger cities operate, with many shared services, spaces, and health systems (Lai et al. 2020). In this regard, those wealthy workers able to exit cities and work remotely are literally safer, both in terms of health conditions as well as their established economic positions, across the health crisis. During this rapid shift to "work from home", or perhaps realistically transition to not working for a great number of people, engagement with digital technology increased dramatically. Online meetings have proliferated and replaced much human-to-human contact across 2020 as a "safe" mode of communication (Hodder 2020). An emergence of new language has accompanied this shift of work online, in itself a quasi-marketing tactic, the rise of "Zoom Fatigue" (Wolf 2020) as a compliment to hyper-capitalism's burnout is a sad reality for many still able to engage with their workplace from home (Walker 1986).

The move to Zoom for work has also been mirrored in higher education globally with higher education workers - academic, professional and students alike - moving rapidly to online conferencing tools to replace face-to-face interactions (Serhan 2020). The move online, termed by many universities as "emergency remote teaching", or for international students "emergency remote offshore teaching," saw dramatic shifts to the pedagogy and mode of work for huge cohorts of students and staff. Quick to distinguishing between "emergency" and business as usual, universities justified their rapid curriculum adaptation, and in some instances dilapidation, as a necessary continuation of "essential" work (Hodges et al. 2020; Rahiem 2020). For many academic staff this transition heralded a newfound collaborative spirit around the teaching and learning process in the pressure-cooker of lockdown, and an engagement with technology - something which may have been previously less than prominent - became a necessity. Suddenly, those with skills in distance and online education became informal, networked leaders in the education space (Fernandez and Shaw 2020). Amongst the scientific community actively researching COVID-19 a rapid opening of research knowledge occurred through fast-paced publication and the use of open access knowledge dissemination networks (Lee and Haupt 2020). Broadly, this global health crisis has created significantly challenging conditions for those in precarious and insecure work. Even amongst knowledge workers with the capacity to move online, there are disproportionate economic effects on those with and without stable employment from people of color, women, and poorer communities (Clark et al. 2020; Dang, Huynh, and Nguyen 2020; Fortuna et al. 2020). For students of these backgrounds across the sector, the move to online learning and teaching had disproportionate impacts as students without access to relatively modern technology, high-speed internet access, or a stable home environment from which to work suffered a lack of socio-economic ability to engage. Respectively, precarious academic workers found themselves with the immediate need to adapt to working from home, teaching from home, and with increasing demand from their institutions to support students of diverse backgrounds. Significantly, this included international students who were dramatically impacted by travel restrictions and health conditions at home (Nguyen and Balakrishnan 2020; Paudel 2020; Supiani et al. 2020).

International students make up the economic lifeblood of many of Australia's eastern coast universities, with high numbers of Chinese students supporting the universities' dangerously ambitious research agendas. Amidst a struggling 
university sector, the crisis of the pandemic has plunged many of Australia's universities into deep uncertainty (Doidge and Doyle 2020). Indeed, recent political conversations have emerged which would see conservative and liberal governments merging and combining universities in a misguided attempt to save, enhance or shuffle the institutions up the international rankings (Siebert 2020). With COVID-19, many international students were suddenly plunged into difficult financial conditions themselves and no longer in a position to pay their exorbitant tuition fees with no support from the government: "we were told by the Prime Minister to pack our bags and leave if we were not able to support ourselves financially" (Sivarajah 2020:35). A spattering of student support from foreign governments and local universities eventually emerged, which ensured select international students were able to either stay in Australia or return to their own country, though government support never came. At our university, international and disadvantaged students were supported through a tailored financial package which went some way towards providing aid for students in difficult economic conditions as a result of the initial lockdown (Our P\&VC announced this package here: Stirling 2020). While student support locally emerged, the Liberal/National Coalition federal government in Australia refused to reasonably support the international students who pay their way to an education in the country (Nguyen and Balakrishnan 2020).

Universities in Australia, already in a difficult position and struggling for relevance, funding, and acting in increasingly cutthroat corporate forms of governance in a race to the bottom, took further hits with many institutions shedding "insider" permanent staff in "necessary" organizational downsizing (Universities Australia 2021). Claims that the government failed to bail out the university sector were ill-received by the public, whose conservative cultural conditioning has worked to position them against any form of "bailout" and a disposition of apathy towards the problems of the university sector. Complicated further by a general perception of universities as ivory towers where privileged professors reside, and an ongoing Liberal Party rhetoric of the university as a societal disservice meant only for the privileged minority destined to Liberal Party politics has created a broad culture of anti-intellectualism.

\section{Moving online and precarious work}

During South Australia's first lockdown, we were both teaching across multiple topics in a handful of disciplines as casual employees with heavy teaching loads. Both of us had fallen trap to the necessity of absorbing as much work as possible as the glimmer of hope for a permanent academic position flashed before our eyes. Just as the depiction of a Chinese epidemic was beginning to make its first appearances in Australian media, we were both in a struggle to take on work across bridging programs, the humanities, and education, balancing what we needed to pay our rent against how much we could manage to teach, mark and support in addition to working on our doctoral studies: the very image of precarious workers in higher education under piles of student papers and swimming through content for multi-disciplinary teaching (O'Connor 2020). While we are both experienced "casual academics," neither of us had ever been offered a contract, let alone a permanent position in the academy. Our contributions across a year equaled in the order of educating 300 students, marking some 1,800 assignments, and making substantial contributions as casual research assistants to a range of projects, including those funded by the prestigious Australian Research Council. The "glory" of working on these projects was an internal victory in ourselves, a kind of "I can do this" attitude to our own detriment.

Neither of us experienced "burnout", as there were certainly substantive crunch points across our working periods. Balanced with the dearth of work across the summer and winter breaks, we could rationalize the exceptional load between us as both a way to pay the bills, the privilege of teaching, and the glimmer of possibility of academic roles at the end of the tunnel. It was not long into our Semester 1, 2020 teaching that the sudden necessity to move online surfaced in the country. With almost no notice and a flurry of activity by insider academics and professional support staff on campus, we were teaching online. As casuals with no paid access to professional learning, and limited access to resources, support, and, honestly, time, there were no bona fide supports for casual tutors moving to online learning and teaching. Both being "young", relatively tech-savvy academics, we were able to stumble our way through using our university's online conferencing environment, collaborate, and with the influx of our students streaming in to collaborate with us, it felt like the sharp learning curve was happening together. Fortunately, our inexperienced students went easy on us, but amongst our casual colleagues there were many without adequate equipment, skills, and 
support to engage with online teaching. In some instances, these peers lost their teaching contracts, easily rescinded by the university and delegated to other eager casuals who had rapidly developed a knack for talking at students for an hour tutorial online.

Balancing Collaborate, Microsoft Teams for our professional communication about the research work we were both managing, and a deluge of emails from students, this was one of the busiest times either of us have ever experienced. The immense stress of juggling this work with next to no human support and no financial support, with a requirement that we redevelop tutorial content and workshop activities on the fly, while the permanent "insider" academics languished with their two or three classes online, created an easily depressive environment in our homes. As with many of those working from home, particularly as a novel experience, having been recently evicted from a shared office in our then College, the boundaries between work and home life blurred. Both of us had experiences of working well into the early hours of the morning writing emails to students, contributing to publications, drafting reports, and revising teaching plans. The slide into "work as life" was, for us, nearly complete. Admittedly, we were taking on a lot of work - work we were capable of doing with a track record of "success", though we could not have predicted the timing of the pandemic and its wide-ranging impacts on our work. We both managed to successfully complete two semesters in 2020 of teaching, though with a substantially reduced load in Semester 2, with positive student evaluations of our teaching and high praise received for our commitment to our student's success, wellbeing, and engagement during the pandemic's lockdowns, though none of this is coming from the university's insider academics. The move online, however, was not the only dramatic change during the pandemic. Casual employment conditions shifted, and the responsibilities of caring for students shifted disproportionately, with student expectations increasing around "care," particularly from female academics (K1nıkoğlu and Can 2021; Nash and Churchill 2020). Across 2020 we both lost substantial amounts of work, partly due to natural attrition of research and teaching work in a pandemic, and in no small part due to changing workplace conditions in the academy and a marked increase in exploitation of precarious workers.

\section{Insecurity, pandemic, and academic women}

The pandemic created employment insecurity across a range of categories, the effects of which were exacerbated for women, particularly those in insecure work (Churchill 2020; Wenham et al. 2020). Educational participation in Australia results in a high number of women "prepared" for skilled work, however, gender segregation leads to women being "more likely to be on the frontline as essential workers putting them even more at risk of being exposed to coronavirus" (Churchill 2020:3). With demands on women increasing for care obligations, be they responsible for their own family and children, or for labor which entails care for others, and labor in the "home workplace," women have been disproportionately disadvantaged in terms of additional unpaid work during the pandemic. Indeed, even amongst those essential researchers in academia, with a disproportionate gender balance towards women in the health professions, correspondence in The Lancet highlights that "at 30\%, 28\%, and 22\%, women's shares of overall, first, and last authorship in COVID-19 papers decreased [in 2020] by 16\%, 23\%, and 16\%, respectively" (Gabster et al. 2020:1969).

The exploitation of women's labor to support men's publishing, work, and academic careers mark a repeat of the patterns of the historical academy. While this phenomenon is far from new, as White (2001) highlighted, corporatization and managerialism have only accelerated the gap between men and women in the academy, and, importantly, even in the 1990s there had been ongoing issues of managerialism and "a negative impact on the work patterns and pay rates of Australian women academics" (White 2001:67). The damaging impacts of capitalist acceleration and a cultural replacement in university management towards managerialism have only amplified the challenges for women in academia. While under the guise of progress, or perhaps while they are ostensibly "in charge," there is a constructed "glass cliff" where academic women can be deliberately placed in positions where their progress is limited by design and their tenure is denied and ultimately reduced to administrative work as opposed to scholarly prestige (Peterson 2015). Moreover, these positions are the vast majority of high-level academic ranks for women (ranks D \& E in Australia) and management are, themselves, an image of precarity, working on borrowed time and power (Stringer et al. 2018). In this space, as academic women begin to "move up" through a constructed 
academic hierarchy - to which hegemonic men are not beholden - they inherit a credulous acceptance of, and even a dependence on, the extant institutional patriarchal systems which exploit women and their labor (Bone 2018). Here, women with "opportunity" to compete in the false labor market are converted to intense dependency, an esprit de corps with the patriarchs - the hegemonic ideal which in reality endlessly pits women against women, including senior academic women against junior academic women, in an exploitative relation which positions women from the beginning of their careers as the hard worker under the academic man and, in many instances, unable to lift other women, even to the point of deliberate sabotage.

In conjunction with the pandemic, the augmentation of the problems with "pipelines" for women through higher education, with the recent proliferation of doctoral students and reductions in total numbers of "insider" stable academic positions, they have always affected women beyond measure. While, in broad terms, educational participation by women in Australia is comparatively high, the pipeline, or pathway, through to stable "insider" work in the academy is still, as White (2001) asserted, leaky. Doctoral programs no longer automatically include high quality academic mentorship or internships into teaching and learning or research processes of the crumbling academy; both of us experienced a complete lack of support from our then supervisors during our shift to emergency remote teaching, both in supervisory capacity in our doctoral education and from our immediate supervisors in the teaching programs we worked in. Indeed, it was almost as though we had disappeared to the entire department. Later we learned about weekly check-ins between "insider" academics, an emanation of support from leadership, including the organization of forums to discuss strategies for online teaching, and several above-and-beyond support measures for those academics to whom a computer is still a scary technological object rather than a tool for educational ends. Our experiences of our then supervisors could certainly be characterized as "exploiter" (Brabazon 2016:15), and, in particular, shone a light back on the sexist relationship between male academics and their female students that is still rampant in academia.

Rather than the mentor-mentee relationship of promise, the female, indeed often feminist, precariat can still unknowingly be trapped in a sexist relationship in which she falls prey to the age-old woman behind the academic man, indeed, a white man of privilege posing himself as a feminist-sympathizer gaining favor and even flanked by his female colleagues for his apparent work for women. The female doctoral student will work hard to contribute substantially to her male academic's research, only for it to be claimed in his name. This accelerated through COVID-19 to the point where a female student could become literally invisible to the institution whilst working from home, enabling the exploitative relationship to expand and, like an eclipse, allowing a subsumption of "her" work into "his". The female junior researcher can easily become a literal housewife to academia if the academy does not protect her or recognize her status as a contributing citizen of the academy (O'Keefe and Courtois 2019). The invisibility of female work in the pandemic meant that women may be unable to take any credit, or be acknowledged in any way, for the work they meaningfully contributed, perhaps due to a toxic male of academic "prowess" that feeds on the labor and flanking of female junior academics, which, critically, must remain junior by necessity for his success. Any glimmer of hope for the future of an academic career that the female precariat might have had was seriously threatened during COVID-19 lockdown, when sexist, white, male academics could not be called out in a see something say something on campus that, at very least, enabled the calling out of exploitation - even if it never resulted in action. Keeping the woman at home made it such that the academy needed to do nothing about the oppression which had been occurring since before the pandemic. The female junior researchers' presence, standing behind the white, able-bodied, heterosexual, academic man rendered them literally invisible to the machinery of the university. Maximizing on the ability to exploit, and scrambling to highlight significance in the academy, now mobilized through the invisibility of the female junior, enabled a vainglorious exploitative male academic to profit, through inaction, from the work of a female precarious "outsider".

\section{Doctoral education and traineeship against the storm}

In late capitalism, university qualifications are aggressively repositioned towards market objectives, from political rhetoric through to university advertising campaigns (Brett 2021; Connell 2013; Gottschall and Saltmarsh 2017). Including an obsessive and accelerating focus on the use of emergent technologies, including virtual reality, 
blockchain, and big data, made to fit with teaching and learning in undergraduate, science, technology, engineering, math, humanities, arts, social sciences, education, law, government, medicine and nursing qualifications - regardless of authentic benefit or even relevance (for example: Eijnatten, Pieters, and Verheul 2013; Kaplan 2015; Kitchin 2014; Rooksby and Dimitrov 2019; Skiba 2017). A subsequent adaptation of teaching and learning towards convenience, a "McDonaldization" of degrees (Nadolny and Ryan 2015), and the decaying value of a qualification for learning or as a fundamental pillar of engaged, critical democracy erodes the very purpose and nature of the scholarly promise in universities. Australian universities find themselves trapped in a self-harm cycle, managerial university executive driving itself towards rapid technological and educational change, driving the cost of the "campus" up, chasing enhanced research outcomes that ignore any actual cultural, social, health, or political benefit, and a federal political system which continues to catastrophically cut, reimagine and redistribute funding and models of higher education. An endless cut, shift, restructure, recreate, move and divide between the soft sciences and hard sciences, the pitting of academics against one another2, an increasing scarcity of jobs, and an endlessly unstable and increasingly mentally draining and damaging university landscape have emerged. This is a scary world for future academics. While it is important to acknowledge that not all students will not necessarily continue beyond an undergraduate or masters qualification, those that do are increasingly taking what is of value from the research process and exporting it into private enterprise to produce more private profit, as the only space with the possibility of stability for the factory production line of quantitative skill Ph.D. holders (Brabazon 2016). The promise of higher education as an institution of learning, sharing knowledge, and democratization briefly realized in the 1970s and 1980s after the dramatic social upheaval and student power movements of the 1960s are but a flash in the historical pan as universities give up on democracy and possibility in favor of corporatization, market competition, deregulation, mergers and fee hikes. The university suffers in an era of students seen singularly as consumers, valued for their market use-value (Brown 2015). The cultural shift in the contemporary capitalist university, itself a bifurcation of academy-as-institution and academy-as-tradition, has seen a departure from the academic community towards use-value profit. Here, an exploitative academic model has been allowed to thrive, enabling a collective value extraction from the precarious worker, often incredibly skilled intellectual laborers, under the banner of attracting research funding and appealing to management hegemony. The secure academic pivots from a scholar to a sales front as their presidents and vicechancellors had only a few years before. Here, the scant few who fight back for equitable working conditions and a return to the 'golden era' of universities voices are drowned out, and while the 1960s image of a university was far from an egalitarian class, race, and gender utopia, it stands starkly as an image against the modern academic malaise or exploitative marketing-man.

A reconceptualization, then, is necessary in order to reposition education and universities in contemporary culture; a move towards a new way that acknowledges the problems, exploitations, and failures of the university institution of the past, which allows for a radical, yet necessary, new university. This need not be implemented in the hallowed halls of Loxbridge, nor the Ivy American university; those that wish to build a new way can. Starting with a relatively weakened, yet employment-stable position of academics of rebellious interest, and through the creation of communities around practice and knowledge sharing the academy qua tradition can find its way back to its purpose as a public good. While leading from the bottom, itself a monumental task, provides its own challenges, the resultant 'metric' uplift, which meshes with fresh modes of being in higher education, is possible together. By casting down the marketing-man in an allegiance of Ph.D., precariat, and tenured activist-scholar, new spaces and ways of working become clearer, though they require a severe commitment to action. This initiative, possible only through a unification of those inside and out of the academy, creates conditions for a shared consciousness of Gramscian tradition. Therefore, in this section, we pose four recommendations to re-center doctoral education as a pathway to change universities for the better.

\section{Research support for Ph.D. students and mentored pathways to research active positions}

Universities have the opportunity to provide support for students who have an identified interest in pursuing a research trajectory. By tailoring mentoring and support programs, universities can re-value doctoral students' contributions, with pay, which would enable thorough research engagement across disciplines. By tailoring a stream in doctoral programs to research-focused students, through a combination of intensified funding for research support 
and training and through new mentorship pathways and incentives for students in the discipline, the possibility that Ph.D. students will "succeed", by metric success, increases dramatically. Valuing contributions and facilitating meaningful learning through research traineeships which, based on evidence and track record, eventuate in contractpathway to permanent research-focused roles for successful participants uniquely solves the problems of immediate tenure and the precariousness of working in academia: the loss of talented researchers under a mountain of marking. Accompanying this must be an incentive structure which encourages research dissemination through community and open access channels. Alongside such a mentorship pathway would come an equal opportunity policy and a gender quota - a still strong mode of encouraging equal gender engagement.

\section{Rebuild teaching internships for Ph.D. students}

Academia has a track record of providing strong mentorship for teaching-focused future academics. While this support has largely evaporated in the massification of doctoral education, there is real potential to reintroduce teaching internships amongst Ph.D. candidates. By providing equal support for research-interested and teaching-interested students, and an inherent ability for students to choose a "stream" or a mandate to complete one year of each offers support for teaching trajectory students in doctoral programs while equipping them with the research skills that come with quality supervision and support. Through new mentoring and training designed specifically for doctoral students and funding avenues for doctoral students to enter into a peer-supervised "teaching academy" which incentivize teaching-focused staff to support doctoral students' development of good pedagogic strategies in their discipline, the cycle of research support and teaching support can be complete. Such an approach, though not entirely novel, gives Ph.D. students support networks, enables collegiality, and creates opportunities for them to experiment in their teaching and research process at a meta-level. Pragmatically, universities would likely use these programs as a filtering system to determine who is able to enter into teaching or research work. While not the purpose of these proposed support schemes, with appropriate and peer-reviewed mechanisms, there is no reason mentoring and pathways to teaching and research could not act as a constructive education toward permanent employment. Indeed, ensuring that students in these pathways were either teaching or researching, being given appropriate financial compensation and scholarly recognition for their work, and having a program designed to support students to develop and deliver their own research as they work would create arguably better working conditions than "insider" academics already have. Importantly, by enabling and facilitating higher degree student's contributions, and counting them in meaningful ways, presents an incentive for both the institution and the rebuilt academic community. In this sense, the universities can count more output, the tenured academic has more access to diversity, and the student embarks on their career visibly sooner without substantive fear of loss of income, reputation or revenue.

\section{Incentivize Ph.D. supervisors to co-publish with students}

Research is valued based on its impact, rank, or the funding it secured. In this regard, funding bodies and universities alike should prioritize and incentivize those grants and publications which are co-authored or supported by doctoral students. Ensuring a partnership plan for working with d octoral students is in place to prevent possible exploitation and rewarding publication, and other research output that works with students is a meaningful way towards ensuring students are part of the culture of the university. This would require the configuration of balanced and research-focused roles such that academics are in a position to be rewarded for co-publishing with their Ph.D. students. Moreover, this supports and protects the fundamental "freedom" provided through academic integrity, one amongst the most significant of the academic tradition's values.

\section{Students in Governance}

Finally, and perhaps most importantly, give students a seat at the table in governance dialogue. Valuing students' contributions in their research and teaching work by providing secure pathways to permanent work goes a long way towards building a sustainable culture. However, ensuring everyone has a voice in governance requires a radical rethink of the way that university governance is currently operated in Australia. There is a deep need to identify students' views on areas for innovation, improvement, and change. In this vein, universities have, distressingly, progressed 
towards increasingly consumer-focused market research tactics in a marketing and market research head spin (Batabyal 2006; Gottschall and Saltmarsh 2017). In order to meaningfully direct higher education for the future, the students must be included in meaningful ways in the strategic decision-making of the university. Vice-Chancellors, Deans, teaching program directors, and teaching staff should use every opportunity to listen to student views, but also to involve students before strategic decisions are made in decisions that affect them - nothing about them without them (Cornelius-Bell and Bell 2020). Rather than focusing on reporting on the "good job" the university has been doing politically and in its research agenda, it should create a culture of ownership amongst undergraduate, graduate, and post-doctoral students and workers. If everyone can feel responsible, secure, and valuable to the institution, the culture of the institution will rocket forward. Students, and precarious workers, are equal stakeholders in academic institutions. Not only do we contribute to a web of knowledge in most of the anglosphere, but students also pay for the opportunity. If education is to run as a business, a fundamental acceptance which seems to have held to the core of many anglophone countries, then students must be considered as critical stakeholders, and their robust engagement must be encouraged. Importantly, however, this cannot be taken problematically; conscious, analytical, and meaningful grassroots education is required to ensure that the dream of a new academy - no longer separated as institution and community - can be achieved together for the benefit of humanity and our planet.

\section{Concluding thoughts}

Higher education globally is in a grim state. Successive attacks of corporate governance structures, neoliberal managerialism, economic rationalism, and metric chasing have left the university sector in ruins. The COVID-19 global pandemic accelerated the exploitation and damage of the university sector to students and workers alike, and as long as it continues to affect the nature of work, the damage will continue. Students still speak to the mental damage of social distance, the global insecurity of health, the inability to access healthcare, the insecure workplaces, worries about the climate and planet, and the world they are inheriting. Alongside students, academics, particularly early career and female academics, struggle with insecurity and anxiety over their work, taking on too much, never knowing if they might lose their job or be exploited by a supervisor or colleague. To make a meaningful difference in late-capitalism, serious intervention into the governance, priorities, and pathways in universities are needed. Across the political economy, the degradation of the nature of work, the boundaries between work and leisure, the security of employment, the access to adequate mental and physical resources, failure of rapid technological advancement to solve societal problems, wealth concentration, and climate change pose significant and wide-ranging problems for students and scholars. There are hopeful ways towards the future, but they require a serious and sustained rethink of what higher education is and does, how culture and representation work, and the nature and future of work in a global era of insecurity, anxiety, and disruption.

We hope to have started another conversation about the nature and value of doctoral education and insecure work in the, hopefully soon, post-COVID age. Our optimistic suggestions here are designed to be improved, interrogated, and adapted. We hope only for attention to be given to the state of higher education globally before it falls into obscurity, collapses into the void of for-profit micro-credentialling, or is altogether shut down by the collapse of the global climate. 


\section{Endnotes}

1. Front-line workers, health care professionals and service industry workers are also under enormous pressures of a similar nature, in a competition to survive, and enable survival, through work.

2. This is constructed within a false labor market where hegemonic necessity breeds competition.
As the hegemonic university leader drives towards ever increasing ranking gains the establishment of hierarchical and extremely competitive spaces are established. Here competition is established as a basic principle of participation in the Civil society of the university (Gramsci 1996).

\section{References}

Afonso, Alexandre. 2013. "How Academia Resembles a Drug Gang." Impact of Social Sciences. Retrieved March 20, 2021 (https://blogs.lse. ac.uk/impactofsocialsciences/2013/12/11/ how-academia-resembles-a-drug-gang/).

Batabyal, Amitrajeet A. 2006. "Shakespeare, Einstein, and the Bottom Line: The Marketing of Higher Education." American Journal of Agricultural Economics 88(3):767-68. doi: 10/fdc48c.

Betti, Eloisa. 2016. "Gender and Precarious Labor in a Historical Perspective: Italian Women and Precarious Work between Fordism and PostFordism." International Labor and Working Class History 89:64-83. doi: http://dx.doi.org/10.1017/ S0147547915000356.

Bone, Kate Daisy. 2019. “I Don't Want to Be a Vagrant for the Rest of My Life': Young Peoples' Experiences of Precarious Work as a 'Continuous Present.'" Journal of Youth Studies 22(9):1218-37. doi: $10.1080 / 13676261.2019 .1570097$.

Brabazon, Tara. 2016. "Winter Is Coming: Doctoral Supervision in the Neoliberal University." International Journal of Social Sciences 3(1):14-34.

Brabazon, Tara. 2020. "From Bad Apples to Zombies? Walking Dead Leadership in the Contemporary University." Fast Capitalism 17(2). doi: 10.32855/ fcapital.202002.009.

Brett, Judith. 2021. "The bin fire of the humanities." The Monthly, March 1.
Brown, Wendy. 2015. Undoing the Demos: Neoliberalism's Stealth Revolution. First Edition. New York: Zone Books.

Churchill, Brendan. 2020. "COVID-19 and the Immediate Impact on Young People and Employment in Australia: A Gendered Analysis." Gender, Work \& Organization 1-12. doi: https://doi.org/10.1111/ gwao. 12563.

Clark, Eva, Karla Fredricks, Laila Woc-Colburn, Maria Elena Bottazzi, and Jill Weatherhead. 2020. "Disproportionate Impact of the COVID-19 Pandemic on Immigrant Communities in the United States." PLOS Neglected Tropical Diseases 14(7):e0008484. doi: 10.1371/journal.pntd.0008484.

Connell, Raewyn. 2013. "The Neoliberal Cascade and Education: An Essay on the Market Agenda and Its Consequences." Critical Studies in Education 54(2):99-112. doi: 10.1080/17508487.2013.776990.

Cornelius-Bell, Aidan, and Piper Bell. 2020. "Partnership as Student Power: Democracy and Governance in a Neoliberal University." Radical Teacher 118(1). doi: https://doi.org/10.5195/rt.2020.738.

Dang, Hai-Anh, Toan Luu Duc Huynh, and Manh-Hung Nguyen. 2020. Does the Covid-19 Pandemic Disproportionately Affect the Poor? Evidence from a Six-Country Survey. SSRN Scholarly Paper. ID 3627054. Rochester, NY: Social Science Research Network.

Doidge, Scott, and John Doyle. 2020. "Australian Universities in the Age of Covid.” Educational 
Philosophy and Theory 0(0):1-7. doi: 10.1080/00131857.2020.1804343.

Eijnatten, Joris van, Toine Pieters, and Jaap Verheul. 2013. "Big Data for Global History: The Transformative Promise of Digital Humanities." BMGN - Low Countries Historical Review 128(4):55-77.

Fernandez, Antonio Arturo, and Graham Paul Shaw. 2020. "Academic Leadership in a Time of Crisis: The Coronavirus and COVID-19.” Journal of Leadership Studies 14(1):39-45. doi: https://doi.org/10.1002/ jls.21684.

Fortuna, Lisa R., Marina Tolou-Shams, Barbara RoblesRamamurthy, and Michelle V. Porche. 2020. "Inequity and the Disproportionate Impact of COVID-19 on Communities of Color in the United States: The Need for a Trauma-Informed Social Justice Response." Psychological Trauma: Theory, Research, Practice, and Policy 12(5):443. doi: 10.1037/tra0000889.

Gabster, Brooke Peterson, Kim van Daalen, Roopa Dhatt, and Michele Barry. 2020. "Challenges for the Female Academic during the COVID-19 Pandemic." The Lancet 395(10242):1968-70. doi: 10.1016/ S0140-6736(20)31412-4.

Giroux, Henry A. 2014. Neoliberalism's War on Higher Education. Chicago, IL: Haymarket Books.

Gottschall, Kristina, and Sue Saltmarsh. 2017. “'You're Not Just Learning It, You're Living It!' Constructing the 'Good Life' in Australian University Online Promotional Videos." Discourse: Studies in the Cultural Politics of Education 38(5):768-81. doi: 10.1080/01596306.2016.1158155.

Gramsci, Antonio. 1996. Selections from the Prison Notebooks. London: Lawrence and Wishart.

Hodder, Andy. 2020. "New Technology, Work and Employment in the Era of COVID-19: Reflecting on Legacies of Research." New Technology, Work and Employment 35(3):262-75. doi: https://doi. org/10.1111/ntwe.12173.

Hodges, Charles, Stephanie Moore, Barb Lockee, Torrey Trust, and Aaron Bond. 2020. "The Difference Between Emergency Remote Teaching and Online Learning." Educause Review 6(1):15.
Kaplan, Frédéric. 2015. "A Map for Big Data Research in Digital Humanities." Frontiers in Digital Humanities 2. doi: 10.3389/fdigh.2015.00001.

Keogh-Brown, Marcus R., Simon Wren-Lewis, W. John Edmunds, Philippe Beutels, and Richard D. Smith. 2010. "The Possible Macroeconomic Impact on the UK of an Influenza Pandemic." Health Economics 19(11):1345-60. doi: https://doi.org/10.1002/ hec. 1554 .

Kitchin, Rob. 2014 . "Big Data, New Epistemologies and Paradigm Shifts." Big Data \& Society 1(1):2053951714528481. doi: $10.1177 / 2053951714528481$.

Kınıkoğlu, Canan Neşe, and Aysegul Can. 2021. "Negotiating the Different Degrees of Precarity in the UK Academia during the Covid-19 Pandemic." European Societies 23(sup 1):S817-30. doi: 10.1080/14616696.2020.1839670.

Lai, Ka Yan, Chris Webster, Sarika Kumari, and Chinmoy Sarkar. 2020. "The Nature of Cities and the Covid-19 Pandemic." Current Opinion in Environmental Sustainability 46:27-31. doi: 10.1016/j.cosust.2020.08.008.

Lee, Jenny J., and John P. Haupt. 2020. "Scientific Globalism during a Global Crisis: Research Collaboration and Open Access Publications on COVID-19.” Higher Education. doi: 10.1007/ s10734-020-00589-0.

Myers, Kyle R., Wei Yang Tham, Yian Yin, Nina Cohodes, Jerry G. Thursby, Marie C. Thursby, Peter Schiffer, Joseph T. Walsh, Karim R. Lakhani, and Dashun Wang. 2020. "Unequal Effects of the COVID-19 Pandemic on Scientists." Nature Human Behaviour 4(9):880-83. doi: 10.1038/ s41562-020-0921-y.

Nadolny, Andrew, and Suzanne Ryan. 2015. "McUniversities Revisited: A Comparison of University and McDonald's Casual Employee Experiences in Australia." Studies in Higher Education 40(1):142-57. doi: 10.1080/03075079.2013.818642.

Nash, Meredith, and Brendan Churchill. 2020. "Caring during COVID-19: A Gendered Analysis of 
Australian University Responses to Managing Remote Working and Caring Responsibilities." Gender, Work \& Organization 27(5):833-46. doi: https://doi. org/10.1111/gwao.12484.

Nguyen, Oanh (Olena) Thi Kim, and Varsha Devi Balakrishnan. 2020. "International Students in Australia - during and after COVID-19." Higher Education Research \& Development 39(7):1372-76. doi: $10.1080 / 07294360.2020 .1825346$.

Norton, Andrew. 2020. “3 Flaws in Job-Ready Graduates Package Will Add to the Turmoil in Australian Higher Education." The Conversation. Retrieved October 20, 2020 (http://theconversation.com/3-flaws-in-jobready-graduates-package-will-add-to-the-turmoil-inaustralian-higher-education-147740).

O’Connor, Sarah. 2020. “The Academic Precariat Deserves Better." Financial Times, December 1.

O'Keefe, Theresa, and Aline Courtois. 2019. “'Not One of the Family': Gender and Precarious Work in the Neoliberal University." Gender, Work \& Organization 26(4):463-79. doi: https://doi.org/10.1111/ gwao. 12346.

Paudel, Pitambar. 2020. "Online Education: Benefits, Challenges and Strategies During and After COVID-19 in Higher Education." International Journal on Studies in Education 3(2):70-85. doi: 10.46328/ijonse.32.

Peterson, Helen. 2016. "Is Managing Academics 'Women's Work'? Exploring the Glass Cliff in Higher Education Management." Educational Management Administration \& Leadership 44(1):112-27. doi: $10.1177 / 1741143214563897$.

Rahiem, Maila. 2020. “The Emergency Remote Learning Experience of University Students in Indonesia amidst the COVID-19 Crisis." International Journal of Learning, Teaching and Educational Research 19:1-26. doi: 10.26803/ijlter.19.6.1.

Rao, Namrata, Anesa Hosein, and Rille Raaper. 2021. "Doctoral Students Navigating the Borderlands of Academic Teaching in an Era of Precarity." Teaching in Higher Education 1-17. doi: 10.1080/13562517.2021.1892058.
Rooksby, John, and Kristiyan Dimitrov. 2019. “Trustless Education? A Blockchain System for University Grades 1." Ubiquity: The Journal of Pervasive Media 6(1):83-88. doi: 10.1386/ubiq_00010_1.

Serhan, Derar. 2020. “Transitioning from Face-to-Face to Remote Learning: Students' Attitudes and Perceptions of Using Zoom during COVID-19 Pandemic." International Journal of Technology in Education and Science 4(4):335-42.

Siebert, Bension. 2020. "Labor Promises Commission on Merging South Australia's Three Top Universities." October 31 .

Sivarajah, Divvya. 2020. "The Cost of Studying in Australia." Advocate: Journal of the National Tertiary Education Union.

Skiba, Editor. 2017. "The Potential of Blockchain in Education and Health Care." Nursing Education Perspectives 38(4):220-21. doi: 10.1097/01. NEP.0000000000000190.

Standing, Guy. 2014. "The Precariat." Contexts 13(4):10-12. doi: 10.1177/1536504214558209.

Stirling, C. 2020. "Flinders COVID-19 Student Support Package: 2 April - Flinders University Students." Flinders University. Retrieved March 15, 2021 (https:// students.flinders.edu.au/coronavirus-information/ update-vc-covid19-student-support-package).

Stringer, Rebecca, Dianne Smith, Rachel SpronkenSmith, and Cheryl Wilson. 2018. "My Entire Career Has Been Fixed Term': Gender and Precarious Academic Employment at a New Zealand University." New Zealand Sociology 33:169-201.

Supiani, Dina Rafidiyah, Yansyah, and Hafizhatu Nadia. 2020. "The Emotional Experiences of Indonesian PhD Students Studying in Australia during the COVID-19 Pandemic." Journal of International Students 10(S3):108-25. doi: 10.32674/jis.v10iS3.3202.

Universities Australia. 2021. "17,000 Uni Jobs Lost to COVID-19." Universities Australia. Retrieved March 20, 2021 (https://www.universitiesaustralia.edu.au/ media-item/17000-uni-jobs-lost-to-covid-19/). 
Walker, Gillian A. 1986. "Burnout: From Metaphor to Ideology." The Canadian Journal of Sociology / Cahiers Canadiens de Sociologie 11(1):35-55. doi: $10.2307 / 3340447$.

Wenham, Clare, Julia Smith, Sara E. Davies, Huiyun Feng, Karen A. Grépin, Sophie Harman, Asha HertenCrabb, and Rosemary Morgan. 2020. "Women Are Most Affected by Pandemics - Lessons from Past Outbreaks." Nature 583(7815):194-98. doi: 10.1038/ d41586-020-02006-z.

White, Kate. 2001. "Women in the Professoriate in Australia." International Journal of Organisational Behaviour 3:64-76.

Williams, Mark. 2020. “Coronavirus Class Divide the Jobs Most at Risk of Contracting and Dying from COVID-19.” The Conversation. Retrieved March 20, 2021 (http://theconversation.com/coronavirus-classdivide-the-jobs-most-at-risk-of-contracting-and-dyingfrom-covid-19-138857).

Wolf, Carolyn Reinach. 2020. "Virtual Platforms Are Helpful Tools but Can Add to Our Stress." Psychology Today. Retrieved March 20, 2021 (https://www.psychologytoday.com/blog/ the-desk-the-mental-health-lawyer/202005/ virtual-platforms-are-helpful-tools-can-add-our-stress). 